\title{
Hemodinamia e Intervencionismo Cardiovascular: ¿evolución o revolución?
}

\section{Haemodynamics and interventional cardiology: evolution or revolution?}

\author{
Darío Echeverri*, Irving Peña, Alberto Suárez y Jaime Cabrales
}

\author{
Servicio de Hemodinamia e Intervencionismo Cardiovascular, Fundación Cardiolnfantil - Instituto de Cardiología, \\ Bogotá, Colombia
}

Recibido el 27 de octubre de 2015; aceptado el 31 de octubre de 2015 Disponible en Internet el 14 de enero de 2016

Tal vez la subespecialidad de la Cardiología que más ha evolucionado en muy corto tiempo es la Hemodinamia; de hecho, la mayoría de especialistas activos han vivido toda su transformación. En menos de tres décadas, se pasó de una hemodinamia básica en pacientes con enfermedad coronaria, enfermedades valvulares y congénitas, angiografía coronaria por vía braquial (técnica de Sones) y angioplastia coronaria transluminal percutánea (ACTP) en lesiones coronarias simples, a una hemodinamia compleja y versátil en presencia de medicamentos, pruebas de reactividad vascular, intervención coronaria compleja, tratamiento percutáneo de enfermedades congénitas, valvulares y estructurales, uso de dispositivos percutáneos nuevos y complejos, técnicas de imágenes intracardiacas e intravasculares, trabajo en equipo en conjunto con cirujanos («heart team»), radiólogos intervencionistas, imaginólogos y anestesiólogos, e incluso terapia híbrida en las nuevas suites de intervencionismo cardiovascular.

Esta evolución ha obligado a que aquellos Servicios de Hemodinamia «cerrados» y prácticamente misteriosos en su práctica clínica, hoy en día sean «abiertos» y multidisciplinarios y hagan que se migre a mejores protocolos de manejo, estrategias de capacitación, mercadeo y alianzas interinstitucionales, que sin duda han redundado en

\footnotetext{
* Autor para correspondencia.

Correo electrónico: decheverri@cardioinfantil.org

(D. Echeverri).
}

resultados óptimos en el diagnóstico y tratamiento de los pacientes con enfermedades cardiovasculares. Hoy no se concibe una institución con «excelencia» en el tratamiento de las enfermedades cardiovasculares, sin la disponibilidad de un Servicio de Intervencionismo Cardiovascular moderno.

\section{La Hemodinamia}

Por definición, la hemodinamia (del griego: hemo: sangre y dynamos: movimiento), es el estudio del movimiento de la sangre a través del sistema vascular. Es difícil imaginar cómo serían los conceptos actuales de las enfermedades cardiovasculares sin los enormes conocimientos fisiológicos y anatómicos derivados de los últimos 60 años de experiencia en el laboratorio de cateterismo cardíaco. André Cournand comentó al recibir el Premio Nobel en 1956, «el catéter cardíaco fue «la llave en la cerradura». Al "girar esta llave», Cournand y sus colegas nos han llevado a una nueva era en la comprensión de la función cardíaca normal y la fisiopatología de las enfermedades cardiovasculares en los seres humanos. Hace tan solo cuatro décadas, Swan y Ganz introdujeron a la práctica clínica un catéter terminado en un balón inflable, en el que el flujo sanguíneo permite llevar la punta hasta la arteria pulmonar.

Hoy en día la medición rutinaria de presiones, flujos y resistencias en las diferentes cámaras del corazón y lechos sistémico y pulmonar, permite la objetivización del compromiso hemodinámico de diferentes condiciones fisiopatológicas, al igual que la decisión para el tratamiento 
temprano y el seguimiento de pacientes con hipertension pulmonar y enfermedades congénitas cardiacas, valvulares y estructurales. El entendimiento de situaciones hemodinámicas especiales, como la condición de bajo gasto y bajo flujo en estenosis valvular aórtica, y el gradiente de presión intramiocárdico en miocardiopatía hipertrófica, hacen de la hemodinamia una evaluación fundamental para el manejo adecuado de muchas condiciones.

\section{Acceso vascular}

El acceso vascular del cateterismo cardíaco y pulmonar ha evolucionado también rápidamente. Desde un enfoque transbronquial, transtorácico izquierdo con posterior punción auricular y punción esternal de la aurícula izquierda, al cateterismo percutáneo a través de venas femorales, yugulares y humerales o arterias radiales, cubitales, braquiales y subclavias. El acceso transhepático, transcavo y translumbar para algunas condiciones puede ser la solución, así como también lo son el cateterismo transeptal y la punción ventricular izquierda apical. En condiciones especiales, los accesos quirúrgicos transapical, transatrial, transaórtico, femoral y subclavio han permitido fortalecer el trabajo en equipo y el avance de las técnicas terapéuticas en condiciones de enfermedades estructurales y de aorta, principalmente.

\section{Intervención coronaria percutánea}

En 1977, Grüentzig introdujo la técnica de la angioplastia coronaria transluminal percutánea (ACTP). Con la evolución vertiginosa de la tecnología y la ampliación de las indicaciones, además de la disponibilidad de los stents, esta técnica que antes rivalizaba y ahora ha superado a la cirugía de bypass en muchas condiciones seleccionadas, hoy es considerada como la modalidad terapéutica predominante para el tratamiento de la enfermedad arterial coronaria. El uso de los stents medicados ha revolucionado la terapia de revascularización miocárdica; hacen parte de la práctica clínica diaria y pueden ser utilizados aproximadamente en un 70 a $90 \%$ de las intervenciones.

Hace varias décadas, los médicos han venido utilizando materiales biodegradables en procedimientos quirúrgicos principalmente. Los cardiólogos intervencionistas han perseguido la posibilidad de un dispositivo endovascular («scaffold») completamente bioabsorbible que actúe como andamio o soporte en la pared y que salvaguarde inicialmente la permeabilidad de la arteria, y luego desaparezca, lo que permite que ésta restaure su integridad fisiológica. La viabilidad de este concepto ha sido investigada por más de 20 años, y hace ya parte de nuestro armamentarium en la práctica diaria.

\section{Intervención percutánea en enfermedades congénitas}

\section{Intervenciones cardiacas fetales}

En 1990, Maxwell, Allan y Tynan fueron los primeros en informar una valvuloplastia aórtica fetal. Desde entonces se han realizado intervenciones cardiacas fetales para algunas enfermedades complejas congénitas del corazón, como la estenosis aórtica, el síndrome de corazón izquierdo hipoplásico con septum intacto o septum interauricular altamente restrictivo, la atresia pulmonar y la estenosis pulmonar crítica con septum interventricular íntegro.

\section{Intervenciones en niños pequeños y recién nacidos}

Desde la introducción de la atrioseptostomía con balón hecha por Rashkind a principios de 1960, el número de intervenciones transcatéter en recién nacidos y lactantes pequeños ha aumentado continuamente. Hoy en día pueden realizarse con seguridad y de forma rutinaria una amplia variedad de procedimientos de intervención en pacientes muy pequeños. Estos procedimientos incluyen algunos paliativos preoperatorios y opciones de tratamiento alternativas a los procedimientos quirúrgicos, tales como la dilatación con balón en estenosis de la válvula pulmonar y un amplio espectro de intervenciones postoperatorias para optimizar los resultados quirúrgicos, la valvuloplastia pulmonar y el stenting en el ductus arterioso en condiciones dependientes de circulación pulmonar; el stenting en arcos aórticos hipoplásicos en condiciones de circulación sistémica dependientes de ductus arterioso, el stenting en el tracto de salida del ventrículo derecho en tetralogía de Fallot severa complicada por arterias colaterales aortopulmonares mayores, la revascularización de fístulas de Blalock-Tausig obstruidas en el postoperatorio, la recanalización de vana cava superior completamente obstruida, el cierre de comunicaciones interventriculares en infantes, el stenting de foramen oval permeable persistente restrictivo en niños pretérmino y el tratamiento percutáneo de estenosis valvular aórtica congénita, entre otras.

\section{Comunicación interauricular}

La mayoría de los defectos del tabique auricular (comunicación interauricular) tipo ostium secundum es susceptible de cierre percutáneo. Muchos dispositivos han sido diseñados para optimizar el éxito del cierre y promover la endotelización rápida del tejido después del implante.

\section{Foramen oval permeable}

Se han propuesto muchos dispositivos de cierre percutáneo para prevenir eventos recurrentes en pacientes con foramen ovale permeable. Hoy en día este procedimiento es rutinario.

\section{Coartación de aorta}

La reparación quirúrgica de la coartación se estableció hace más de 60 años, y la dilatación con balón se introdujo 30 años después. En la práctica clínica, las indicaciones para el tratamiento percutáneo casi siempre incluyen criterios que son recomendaciones de clase ।. 


\section{Comunicación interventricular}

Desde 1987 vienen utilizándose diferentes dispositivos que fueron diseñados originalmente para el cierre del conducto arterioso persistente y defectos del tabique auricular. Ya se cuenta con dispositivos diseñados específicamente para el cierre de comunicación interventricular (CIV) muscular.

\section{Fístulas arteriovenosas}

La terapia percutánea de estas fístulas se basa en la liberación endovascular de uno o múltiples coils, que inducen la trombosis del vaso nutriente, con una alta posibilidad de éxito y bajo riesgo de complicaciones, y en algunos casos el implante de stents recubiertos y la embolización de microesferas.

\section{Intervención percutánea de enfermedades valvulares}

\section{Estenosis valvular aórtica}

La estenosis aórtica valvular es una enfermedad de aparición creciente, a medida que se tienen poblaciones con mayor edad. El reemplazo de la válvula aórtica transcatéter (TAVR) comenzó con un procedimiento realizado por Davies en 1965 en perros. En 2002, Cribier et al. la efectuaron por primera vez en seres humanos. Pocos años después, en 2006, Webb et al. desarrollaron una versión transarterial retrógrada exitosa. Entre tanto, la primera válvula autoexpandible implantada en posición aórtica fue reportada por Grube et al. en Alemania en 2005. Otras vías de acceso vascular descritas en la misma época incluyen acceso transapical, implantación transaórtica a través de miniesternotomía y acceso subclavio, transaxilar y a través de la arteria carótida izquierda.

Se han empleado varios dispositivos, los cuales se componen de un stent de acero inoxidable expandible con balón o autoexpandible de nitinol, tejido valvular con tres valvas de pericardio bovino o porcino, y un manguito de tejido de tereftalato de polietileno. Así mismo, se han hecho importantes avances en su diseño, con lo que se han obtenido mejores resultados clínicos y menos complicaciones (bloqueo AV con implante de marcapaso, insuficiencia valvular y fugas paravalvulares). Ya se dispone de nuevas válvulas aórticas percutáneas y se avanza en estudios clínicos para evaluar su eficacia y seguridad.

\section{Implante de válvula-en-válvula}

El implante de una válvula cardíaca transcatéter (THV) con la técnica de valve-in-valve viene convirtiéndose en una opción de tratamiento viable, reproducible y de bajas implicaciones en pacientes de alto riesgo o inoperables con tejido valvular degenerado. La técnica consiste en implantar una nueva válvula en el interior de la bioprótesis quirúrgica degenerada.

\section{Estenosis pulmonar valvular}

La terapia transcatéter de la estenosis valvular pulmonar es la primera intervención con catéter que ha facilitado la aplicación de esta tecnología en los niños, de modo que muchos de ellos pueden beneficiarse de un tratamiento menos invasivo de los defectos cardíacos congénitos estructurales.

\section{Implante de válvula pulmonar transcatéter}

La indicación más frecuente para el reemplazo de la válvula pulmonar es una lesión residual después de la reparación quirúrgica de cardiopatías congénitas como atresia pulmonar, comunicación interventricular, tetralogía de Fallot, síndrome de válvula pulmonar ausente, tronco arterial común (tronco arterioso), reparación de transposición de tipo Rastelli, defectos interventriculares con estenosis pulmonar, o atresia pulmonar, homoinjerto en la salida pulmonar, por ejemplo, después de la operación Ross, entre muchas otras.

\section{Estenosis de la válvula mitral}

Desde su introducción en 1984 por Inoue et al. la valvuloplastia mitral percutánea con balón ha sido utilizada con éxito como una alternativa para la comisurotomía mitral quirúrgica en pacientes con estenosis mitral reumática. Hoy en día esta técnica es la forma preferida de terapia para el alivio de la estenosis mitral para un grupo seleccionado de pacientes con estenosis mitral sintomática.

\section{Estenosis de válvula tricúspide}

La valvuloplastia tricúspide percutánea se realiza con una técnica similar a la utilizada en la valvuloplastia mitral. Tanto con la técnica de doble balón como con la técnica de Inoue se han obtenido buenos resultados.

\section{Insuficiencia de la válvula mitral}

Existen varios enfoques percutáneos para la reparación de la insuficiencia mitral que afectan múltiples áreas del complejo aparato de la válvula mitral. Terapias en los folletos valvulares incluyen la reparación de borde a borde (E-Valve o MitraClip; Abbott Vascular, Menlo Park, CA, USA), técnicas ocupantes de espacio, y ablación del folleto valvular. La anuloplastia puede ser indirecta, como enfoque a través del seno coronario o enfoque asimétrico. La anuloplastia también puede ser directa, como cincha mecánica (Mitralign, Accucinch, Millipede), cinchado mediado por energía, o enfoque híbrido. Los implantes de cuerdas se pueden insertar de forma percutánea a través de un acceso transapical y abordaje transeptal. De igual forma ha venido desarrollándose el reemplazo de la válvula mitral percutánea con los sistemas Endovalve-Herrmann (Endovalve) y CardiAQ (CardiAQ). 


\section{Otras intervenciones percutáneas}

Se han hecho importantes avances en intervenciones percutáneas de estenosis de la arteria pulmonar, estenosis de venas pulmonares, intervención de miocardiopatía hipertrófica obstructiva con catéter mediante ablaciones septales con alcohol (ASA), aneurismas de aorta torácica y abdominal, y oclusión de auriculilla izquierda en pacientes con fibrilación auricular y alto riesgo de embolia; dispositivos de asistencia ventricular implantables para el tratamiento de la falla cardiaca, dispositivos para monitorización hemodinámica, denervación de arterias renales en pacientes con hipertensión arterial resistente, terapia de activación barorrefleja y terapia celular para el tratamiento de la insuficiencia cardíaca utilizando células mononucleares totales de la médula ósea, factores estimulantes (G-CSF) que movilizan células mononucleares, células madre mesenquimales derivadas de la médula, células madre cardiacas, células derivadas de mioblastos esqueléticos o células regenerativas derivadas de tejido adiposo.

\section{Integración de imágenes}

Las técnicas de imagen también han avanzado para facilitar los procedimientos enunciados anteriormente y ayudar al intervencionista a realizarlos de la mejor manera posible. En la actualidad el ecocardiografista e intervencionista han desarrollado una interdependencia importante para obtener el mejor resultado del procedimiento, reduciendo el tiempo, la tasa de complicaciones y la dosis de radiación. Con el avance de imágenes obtenidas en tiempo real por vía transesofágica tridimensional (3DTEE), ETE2D e intracardiaca se han convertido en casi indispensables debido a las dimensiones espaciales que pueden proporcionar.

Por último, esta revolución clínico-tecnológica en constante crecimiento y renovación aquí reseñada, es la respuesta a las necesidades del paciente en cuanto a seguridad y buenos resultados, desde el diagnóstico simple hasta el más complejo de los procedimientos, garantizándosele así una pronta recuperación y el reintegro a su vida normal. 